\title{
Tropospheric Degradation of Perfluorinated Aromatics: A Case of Hexafluorobenzene
}

\author{
Goran Kovačević, Aleksandar Sabljić*
}

Ruđer Bošković Institute, Division of Physical Chemistry, POB 180, HR-10002 Zagreb, Croatia

* Corresponding author's e-mail address: sabljic@irb.hr

RECEIVED: January 13, 2016 * REVISED: February 1, 2016 * ACCEPTED: February 1, 2016

THIS PAPER IS DEDICATED TO DR. SVETOZAR MUSiĆ ON THE OCCASION OF HIS 707h BIRTHDAY

\begin{abstract}
The major tropospheric removal process for hexafluorobenzene is its oxidation by hydroxyl (OH) radicals. However, there is no information on the reaction mechanism of this important process. All geometries and energies significant for the tropospheric degradation of hexafluorobenzene were characterized using the MP2/6-311+G(d,p) and/or $\mathrm{G} 3$ methods. It was found out that the addition of $\mathrm{OH}$ radical to hexafluorobenzene proceeds via a prereaction complex. In the prereaction complex the $\mathrm{OH}$ radical is almost perpendicular to the aromatic ring and oxygen is pointing to its center. The reaction rate constants for addition of $\mathrm{OH}$ radical to hexafluorobenzene were determined for the temperature range 230-330 K, using RRKM theory and corrected G3 energies. For the whole range of environmentally relevant temperatures $(230-330 \mathrm{~K})$ there is a very good qualitative agreement between the calculated and experimental rate constants. Finally, our results almost perfectly reproduce the unusually weak temperature dependence for $\mathrm{OH}$ radical addition to hexafluorobenzene.
\end{abstract}

Keywords: G3 and MP2 methods; tropospheric degradation; hexafluorobenzene; RRKM theory; particle-in-the-box approximation.

\section{INTRODUCTION}

$\mathbf{R}$ EACTION with the hydroxyl $(\mathrm{OH})$ radical is the primary chemical loss channel for organic compounds emitted into the troposphere ${ }^{[1-5]}$ and a large number of experimental[ ${ }^{[1,5]}$ and theoretical studies ${ }^{[4,6]}$ has been published in this research area. The large fraction of those studies have been carried out for almost all classes of aliphatic organic compounds, i.e. alkanes or alkenes and their halogenated derivatives, alcohols, ethers, carbonyl compounds, organic acids and esters, and have revealed the reaction-path dynamics and the reaction kinetics for tropospheric degradation of those chemicals. Contrary to this, the number of studies on aromatic compounds is quite limited. The detailed investigations on reaction mechanisms and reaction kinetics are available only for benzene, ${ }^{[7,8]}$ toluene, ${ }^{[9]}$ fluorobenzene, ${ }^{[10]}$ chlorobenzene, ${ }^{[11,12]}$ phenol[13] and naphthalene. ${ }^{[14]}$ The major reason for a small number of studies on aromatic compounds is their significant size and complex reaction mechanism with $\mathrm{OH}$ radicals, thus sophisticated theoretical methods must be used in order to obtain meaningful results.
Our long-term research goal is to develop affordable and reliable methodologies for calculating the tropospheric lifetime or removal rate of large molecular systems. ${ }^{[15-18]}$ We have successfully developed a reliable methodology for the reaction rate constants and tropospheric lifetime of fluorinated alkanes ${ }^{[19]}$ and halogenated alkenes. ${ }^{[18,20,21]}$ In the last several years, we are extending those research efforts into the tropospheric degradation reactions of halogenated aromatic hydrocarbons and were successful in modeling gas-phase reactions of $\mathrm{OH}$ radicals with fluorobenzene ${ }^{[10]}$ and chlorobenzene. ${ }^{[12]}$ This study on hexafluorobenzene is the next step in our endeavor to produce methodology for calculating the tropospheric degradation rates of persistent organic pollutants (POPs), ${ }^{[22,23]}$ normally perhalogenated or polyhalogenated biphenyls, diphenylethers, dibenzo-p-dioxins or -furans, and analogous chemicals (DDT, chlordane, heptachlor).

Hexafluorobenzene is a modeling compound for perfluorinated and polyfluorinated aromatic compounds. The major tropospheric degradation process of hexafluorobenzene is its oxidation by $\mathrm{OH}$ radicals $^{[1]}$ and the only 
relevant pathway is the addition of $\mathrm{OH}$ radical to the aromatic ring, Equation 1.

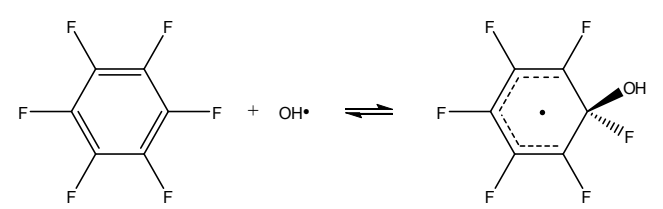

However, only a limited data are available on the tropospheric degradation of hexafluorobenzene. The recommended room-temperature $(298 \mathrm{~K})$ reaction rate constant for $\mathrm{OH}$ radical addition to hexafluorobenzene ${ }^{[1]}$ is $1.71 \times 10^{-13} \mathrm{~cm}^{3}$ molecule ${ }^{-1} \mathrm{~s}^{-1}$ while the most recent measurement ${ }^{[24]}$ suggests a somewhat lower room-temperature (294 K) reaction rate, i.e. $1.52 \times 10^{-13} \mathrm{~cm}^{3}$ molecule $\mathrm{e} \mathrm{s}^{-1}$. However, there is no information on the reaction mechanism or reaction-path dynamics of this important tropospheric degradation process. Thus, the main objective of this study is to obtain valuable missing information on the reaction mechanism and kinetics of hexafluorobenzene oxidation by hydroxyl radical.

In our previous studies on monosubstituted halobenzenes, ${ }^{[10,12]}$ it was proven that theoretical methods MP2 and G3 can give relevant information on the reaction mechanism of $\mathrm{OH}$ radical addition to haloaromatic systems as well as on the corresponding thermodynamic data. Those results coupled with the RRKM (Rice-RamspergerKassel-Marcus) kinetic theory have also successfully reproduced the experimental reaction rates. In this study we will apply an analogous approach to obtain missing information on the reaction mechanism and reaction-path dynamics of hexafluorobenzene.

\section{COMPUTATIONAL METHODS}

Optimized geometries were calculated using MP2/6-311G(d,p) method and confirmed by frequency calculations. Unrestricted wavefunction was used for radical species. IRC (intrinsic reaction coordinate) calculations were performed to confirm connection between the transition state and minima on each reaction pathway using Gonzales-Schlegel's method in mass weighted coordinates. ${ }^{[25]}$ Geometry, frequency and IRC calculations were performed using GAMESS program. ${ }^{[26]}$ Single point energies were calculated with G3 method ${ }^{[27,28]}$ using Gaussian program package. ${ }^{[29]}$

Geometry of prereaction complex is optimized with a very tight gradient cutoff $\left(10^{-7} \mathrm{Ha} \mathrm{Bohr}^{-1}\right)$ and projection of the Hessian matrix was used in the normal mode calculation in order to remove translational and rotational contaminants. ${ }^{[30]}$ These normal modes were examined and normal mode describing dissociation of the prereaction complex is selected. Several geometries were generated along that mode by extending separations of the $\mathrm{OH}$ radical and hexafluorobenzene. Geometries with separations from 3.6 to $25 \AA$ i were examined. At large separations geometries were optimized with the frozen distance and angles between $\mathrm{OH}$ radical and hexafluorobenzene. Energies from these points were extrapolated by cubic spline to achieve sufficient density of points. Rotational potential was calculated at these points for series of temperatures and was added to the electronic potential. The loose transition state was determined for each temperature by locating maxima on the $\mathrm{OH}$-hexafluorobenzene potential.

Geometry and energy data were used in the reaction rate constant calculations. All frequencies were scaled by 0.941 before using them in the thermodynamic and density of states calculations. The tropospheric oxidation of hexafluorobenzene [Eq. 1] was divided into two steps [Eq. 2]. The first step is the formation of prereaction complex and the second step is rearrangement of the prereaction complex into an adduct.
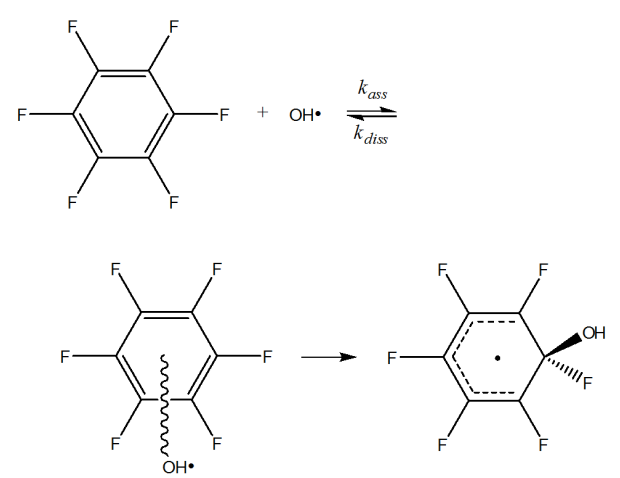

Equilibrium constant $(K(T))$ for the first step was calculated using the statistical thermodynamics calculations. The reaction rate constant $\left(k_{\text {diss }}\right)$ was calculated for dissociaton of the prereaction complex using RRKM method $^{[31,32]}$ in the high pressure limiting regime. These two constants define the rate of association reaction $\left(k_{\text {ass }}\right)$. The fate of prereaction complex is modeled with the exact Gillespie stochastic method. The overall reaction rate for addition of $\mathrm{OH}$ radical to hexafluorobenzene $\left(k_{\text {calc }}\right)$ was calculated according to Equation 3:

$$
k_{\text {calc }}=f \times k_{\text {diss }} \times K(T)
$$

where $f$ is the final relative population for the adduct, after the Gillespie simulation with 1000 collisions in bath-gas. ${ }^{[33]}$ Reaction (2) is assumed to proceed from the activated complex and its activation energy is equal to the well depth. All frequencies, used in the density of states calculation are the 
scaled harmonic frequencies, except normal modes that describe internal rotation of the $\mathrm{OH}$ group. These degrees of freedom were treated as internal rotors and barrier of the internal rotation was calculated by scanning the rotational potential of the $\mathrm{OH}$ group. Furthermore, as demonstrated in our previous studies, ${ }^{[10,12]}$ the relative translation of $\mathrm{OH}$ radical with respect to hexafluorobenzene in the prereaction complex was treated as a two-dimensional particle-in-the-box and the box size was set at $2.8 \AA$ which is the diameter of benzene ring.

Energy transfer, used in the Gillespie stochastic modeling, between prereaction complex and bath gas was modeled with the exponential down collision model at pressure of 1 atmosphere. Since tropospheric reactions were modeled, nitrogen was used as the bath gas. The potential between prereaction complex and nitrogen molecule is modeled as a Lennard-Jones potential. The Lennard-Jones parameters were determined from the position and depth of potential minimum calculated from atomic parameters taken from the General Amber Force Field (GAFF). ${ }^{[34]}$ A potential was calculated as a mean potential of 18432 potentials at different relative orientations of nitrogen and prereaction complex at a given center of mass distance. Calculated parameters are: $\sigma=$ $4.96 \AA, \varepsilon / k_{\mathrm{B}}=271.0 \mathrm{~K}$. Intramolecular vibrational energy transfer is neglected. Energy transfer parameters are unknown for this system and a value of $175 \mathrm{~cm}^{-1}$ was assumed for exponential down model by analogy with monohalogenated benzenes. ${ }^{[10,12]}$ Energy density was integrated by double array integration scheme with $7 \mathrm{~cm}^{-1}$ energy grain. The maximum energy from the coarser part of the double array was fixed at $85000 \mathrm{~cm}^{-1}$. These values were checked by examining if the final result differs significantly when values were subjected to variation.

All reaction rate and thermodynamic calculations were performed with the MULTIWELL program package. ${ }^{[33,35,36]}$

\section{RESULTS AND DISCUSSION}

\section{Optimized Geometries and Formation of Prereaction Complex}

The optimized geometrical parameters of all stationary points are shown in Table S1 (Supporting Information). The addition of $\mathrm{OH}$ radical to hexafluorobenzene proceeds indirectly via the prereaction complex and is shown in Figure 1. In the prereaction complex the $\mathrm{OH}$ radical is perpendicular to the aromatic ring and oxygen atom is pointing towards its center. An analogous complex was recently published for hexafluorobenzene and hydrogen fluoride. ${ }^{[37]}$ The separation between $\mathrm{OH}$ radical oxygen and aromatic ring is $2.76 \AA$ and the stabilization energy of prereaction complex with

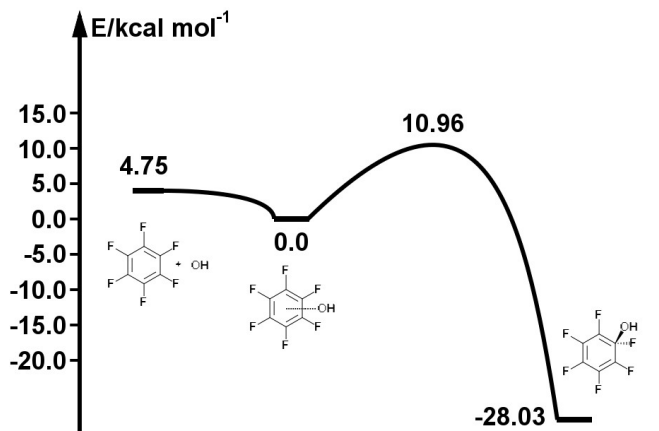

Figure 1. Schematic energy path for the addition of $\mathrm{OH}$ radical to hexafluorobenzene. The values obtained with $\mathrm{G} 3$ method are enthalpies relative to prereaction complex in kcal mol-1.

respect to reactants is about $4.8 \mathrm{kcal} \mathrm{mol}^{-1}$. It seems to be due to the electrostatic interaction between the negatively charged oxygen atom and positively charged aromatic ring due to the strong electron withdrawing power of six fluorine atoms. Recent results on the electrostatic potential of hexafluorobenzene and fluorobenzene ${ }^{[38]}$ corroborate this assumption. It should be also noted that the structure of prereaction complexes is different from the one obtained for fluorobenzene ${ }^{[10]}$ and chlorobenzene ${ }^{[12]}$ where the hydrogen atom of $\mathrm{OH}$ radical is pointing towards the aromatic ring.

Vibrational frequencies of the prereaction complex are similar to the frequencies of isolated $\mathrm{OH}$ radical and hexafluorobenzene except for some low frequencies corresponding to the relative motions of the $\mathrm{OH}$ radical and hexafluorobenzene and which are critical for the title reaction. Two of those degrees of freedom correspond to the nearly free movement of the $\mathrm{OH}$ radical across the aromatic ring plain. By such motions, $\mathrm{OH}$ radical can approach each of the aromatic carbons and create a covalent $\mathrm{C}-\mathrm{O}$ bond with it.

\section{Rearrangement of Prereaction Complex Into the Adduct}

The prereaction complex has a flat potential energy surface which enables the large amplitude motions of the $\mathrm{OH}$ radical. Such motions enable the oxygen atom in $\mathrm{OH}$ radical to approach each carbon atom in the benzene ring. Once oxygen atom is in the vicinity of a specific carbon atom, those atoms start to attract each other. Consequently, the carbon atom at reaction center is displaced from the aromatic ring plain which results in a significant deformation of aromatic system and the increase in its energy. At this stage, the transition state is formed for the addition of $\mathrm{OH}$ radical to hexafluorobenzene. The reaction barrier is $6.2 \pm 1.1 \mathrm{kcal} \mathrm{mol}^{-1}$. In the transition state, the orientation of $\mathrm{OH}$ radical is approximately parallel with the aromatic 
ring and the reacting carbon atom is about $0.2 \AA$ above the ring plain. The distance between $\mathrm{OH}$ radical oxygen and reacting carbon atom is $1.96 \AA$. The $\mathrm{C}-\mathrm{O}$ bond formation and relaxation of the aromatic ring lower the energy of adduct and it slides into a deep potential well of about $28 \mathrm{kcal} \mathrm{mol}^{-1}$.

\section{Reaction Rates}

In our previous studies, ${ }^{[10,12]}$ it was necessary to correct G3 reaction barriers and prereaction complex well depth for their uncertainty in $\mathrm{G} 3$ calculations $^{[39]}$ and to treat the relative translation of $\mathrm{OH}$ radical and monohalogenated benzenes as a two-dimensional particle-in-the-box, in order to reproduce the experimental reaction rates for the addition of hydroxyl radical as well as to account for their unusual temperature dependence. The same approach was applied in the present study by lowering the prereaction complex well and reaction barriers for $0.7 \mathrm{kcal} \mathrm{mol}^{-1}$ and the calculated reaction rates for addition of hydroxyl radical to hexafluorobenzene are reported in Table 1 together with the measured data. ${ }^{[24]}$ The rate constants $f_{\mathrm{i}}, k_{\text {diss }}$ and $K(T)$ used to calculate the reaction rate constants for $\mathrm{OH}$ radical addition to hexafluorobenzene are given in the Supporting Information (Table S2).

Table 1. Comparison of calculated $\left(k_{\text {calc }}\right)$ and experimental $\left(k_{\text {exp }}\right)$ reaction rates $\left(\mathrm{cm}^{3}\right.$ molecule $\left.\mathrm{e}^{-1} \mathrm{~s}^{-1}\right)$ for the addition of $\mathrm{OH}$ radical to hexafluorobenzene.

\begin{tabular}{cccc}
\hline$T / K$ & $k_{\text {calc }}$ & $T / K$ & $k_{\text {exp }}{ }^{(a)}$ \\
\hline 330 & $0.81 \times 10^{-13}$ & 377 & $(3.00 \pm 0.18) \times 10^{-13}$ \\
& & 327 & $(2.15 \pm 0.12) \times 10^{-13}$ \\
320 & $0.76 \times 10^{-13}$ & & \\
310 & $0.71 \times 10^{-13}$ & & \\
300 & $0.64 \times 10^{-13}$ & & \\
290 & $0.60 \times 10^{-13}$ & & \\
280 & $0.52 \times 10^{-13}$ & & \\
270 & $0.46 \times 10^{-13}$ & & $(1.32 \pm 0.09) \times 10^{-13}$ \\
260 & $0.42 \times 10^{-13}$ & 260 & $(1.09 \pm 0.06) \times 10^{-13}$ \\
250 & $0.33 \times 10^{-13}$ & & \\
240 & $0.27 \times 10^{-13}$ & & $(0.79 \pm 0.042) \times 10^{-13}$ \\
230 & $0.18 \times 10^{-13}$ & & \\
\hline
\end{tabular}

(a) Reference 24. Stated uncertainties of the experimental rate constants reflect the estimated overall uncertainty of $\pm 30 \% .^{[1]}$
For the whole range of environmentally relevant temperatures $(230-330 \mathrm{~K}$ ) there is a very good qualitative agreement between the calculated and experimental rate constants. For the whole temperature range there is almost a constant difference between the calculated and experimental rate constants. Namely, the calculated rate constants are always lower by a factor of 2.6 from the respective measured rate constants. This means that the calculated rate constants almost perfectly reproduce the unusually weak temperature dependence ${ }^{[24]}$ for $\mathrm{OH}$ radical addition to hexafluorobenzene. The main reason for the observed discrepancy between calculated and experimental rate constants seems to be the inability to adequately treat the anharmonicity of all five low vibrational frequencies corresponding to the relative motions of the $\mathrm{OH}$ radical and hexafluorobenzene. Finally, a close correspondence between calculated and experimental rate constants indirectly also supports the high quality of thermodynamic data obtained by MP2/6-311G(d,p) and G3 methods as well as the suggested reaction mechanism.

\section{Environmental Implications}

Based on the calculated reaction rate at the average Earth's tropospheric temperature $(277 \mathrm{~K})^{[40]}$ and the global tropospheric $\mathrm{OH}$ radicals concentration averaged over $24 \mathrm{~h}$ period $\left(9.7 \times 10^{5} \mathrm{~cm}^{-3}\right),{ }^{[41]}$ the tropospheric lifetime is estimated for hexafluorobenzene by the following equation:

$$
\tau=1 /\left(k_{\text {calc }} \times[\mathrm{OH}]\right)
$$

The calculated reaction rate at $277 \mathrm{~K}\left(k_{\text {calc }}=0.502 \times\right.$ $10^{-13} \mathrm{~cm}^{3}$ molecule ${ }^{-1} \mathrm{~s}^{-1}$ ) was interpolated from the calculated rate constants at 270 and $280 \mathrm{~K}$. The estimated tropospheric lifetime of hexafluorobenzene is 237 days which indicates its status as a potential POP chemical.

There is no information about the stable reaction products of $\mathrm{OH}$ radical addition to hexafluorobenzene or other perhalogenated benzenes. Thus, by analogy with the tropospheric reactions of various monosubstituted benzenes $\left(\mathrm{X}-\mathrm{C}_{6} \mathrm{H}_{5}, \mathrm{X}=\mathrm{H}, \mathrm{CH}_{3}, \mathrm{OH}, \mathrm{F}, \mathrm{Cl}\right.$, etc.), ${ }^{[42,43]}$ it seems that for the $\mathrm{OH}$ radical addition to hexafluorobenzene the major ring-retaining product will be pentafluorophenol produced by a simple elimination of fluorine atom from the adduct [Eq. 5].

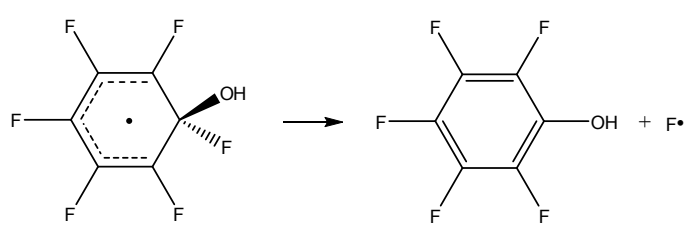


It is well established ${ }^{[42]}$ that adducts produced by $\mathrm{OH}$ radical addition to aromatic compounds are "hot" species with a significant amount of excess energy. For the hexafluorobenzene adduct this excess energy is more than $30 \mathrm{kcal} \mathrm{mol}^{-1}$ (Figure 1). Such amount of excess energy must be sufficient to remove the fluorine atom from the respective adduct and, thus, the formation of pentafluorophenol from the "hot" adduct should be thermodynamically and kinetically feasible.

Supporting Information. Supporting information to the paper is enclosed to the electronic version of the article at: http://dx.doi.org/10.5562/cca2823. Tables listing optimized geometries of hydroxyl radical, hexafluorobenzene, prereaction complex, transition state and adduct, as well as the equilibrium constants for the association of $\mathrm{OH}$ radical and hexafluorobenzene into the prereaction complex, the unimolecular reaction rates for dissociation of the prereaction complex and final relative populations of adduct after 1000 collisions were modeled with the Gillespie stochastic model.

Acknowledgment. This work has been supported by the Croatian Ministry of Science, Education and Sport, under Project No. 098-0982915-2944. Some calculations for this work are done on Isabella cluster of the Computing Center of the University of Zagreb (SRCE).

\section{REFERENCES}

[1] R. Atkinson, Gas-Phase Tropospheric Chemistry of Organic Compounds in Journal of Physical and Chemical Reference Data Monograph No. 2, American Chemical Society, Washington, DC and American Institute of Physics, Woodbury, NY, 1994.

[2] R. Atkinson, Chem. Rev. 1985, 85, 69.

[3] A. Sabljic, W. Peijnenburg, Pure. Appl. Chem. 2001, 73, 1331.

[4] L. Vereecken, J. S. Francisco, Chem. Soc. Rev. 2012, 41, 6259.

[5] R. A. Cox, Chem. Soc. Rev. 2012, 41, 6231.

[6] H. Guesten, Z. Medven, S. Sekusak, A. Sabljic, SAR QSAR Environ. Res. 1995, 4, 197.

[7] C. Chen, J. W. Bozelli, J. T. Farrel, J. Phys. Chem. A 2004, 108, 4632.

[8] I. V. Tokmakov, M. C. Lin, J. Phys. Chem. A 2002, 106, 11309.

[9] I. Suh, D. Zhang, R. Zhang, L. Molina, M. J. Molina, Chem. Phys. Lett. 2002, 364, 454.

[10] G. Kovacevic, A. Sabljic, J. Comput. Chem. 2013, 34, 646.

[11] M. G. Bryukov, V. D. Knyazev, W. M. Gehling, B. Dellinger, J. Phys. Chem. A 2009, 113, 10452.
[12] G. Kovacevic, A. Sabljic, Chemosphere 2013, 92, 851.

[13] M. J. Lundquist, L. A. Eriksson, J. Phys. Chem. B 2000, $104,848$.

[14] Z. J. Zhang, L. Lin, L. M. Wang, Phys. Chem. Chem. Phys. 2012, 14, 2645.

[15] S. Sekusak, H. Guesten, A. Sabljic, J. Chem. Phys. 1995, 102, 7504.

[16] S. Sekusak, K. R. Liedl, B. M. Rode, A. Sabljic, J. Phys. Chem. A 1997, 101, 4245.

[17] Sekusak, S., M. Cory, R. Bartlett, A. Sabljic, J. Phys. Chem. A 1999, 103, 11394.

[18] I. Ljubic, A. Sabljic, J. Phys. Chem. A 2002, 106, 4745.

[19] S. Sekusak, A. Sabljic, J. Phys. Chem. A 2001, 105, 1968.

[20] S. Sekusak, K. R. Liedl, A. Sabljic, J. Phys. Chem. A 1998, 102, 1583.

[21] I. Ljubic, A. Sabljic, J. Phys. Chem. A 2005, 109, 2381.

[22] F. Wania, D. Mackay, Environ. Sci. Technol. 1996, 30, 390A.

[23] A. Sabljic, Chemosphere 2001, 43, 363.

[24] A. Mcllroy and F. P. Tully, J. Phys. Chem. 1993, 97, 610.

[25] C. Gonzales, M. B. Schlegel, J. Phys. Chem. 1990, 94, 5523.

[26] GAMESS - M. W. Schmidt, K. K. Baldridge, J. A. Boatz, S. T. Elbert, M. S. Gordon, J. J. Jensen, S. Koseki, N. Matsunaga, K. A. Nguyen, S. Su, T. L. Windus, M. Dupuis, J. A. Montgomery, J. Comput. Chem. 1992, 14, 1347.

[27] L. A. Curtiss, K. Raghavachari, P. C. Redfern, V. Rassolov, J. A. Pople, J. Chem. Phys. 1998, 109, 7764.

[28] L. A. Curtiss, P. C. Redfern, K. Raghavachari, V. Rassolov, J. A. Pople, J. Chem. Phys. 1999, 110, 4703.

[29] Gaussian 03, Revision C.02, M. J. Frisch, G. W. Trucks, H. B. Schlegel, G. E. Scuseria, M. A. Robb, J. R. Cheeseman, J. A. Montgomery, Jr., T. Vreven, K. N. Kudin, J. C. Burant, J. M. Millam, S. S. Iyengar, J. Tomasi, V. Barone, B. Mennucci, M. Cossi, G. Scalmani, N. Rega, G. A. Petersson, H. Nakatsuji, M. Hada, M. Ehara, K. Toyota, R. Fukuda, J. Hasegawa, M. Ishida, T. Nakajima, Y. Honda, O. Kitao, H. Nakai, M. Klene, X. Li, J. E. Knox, H. P. Hratchian, J. B. Cross, V. Bakken, C. Adamo, J. Jaramillo, R. Gomperts, R. E. Stratmann, O. Yazyev, A. J. Austin, R. Cammi, C. Pomelli, J. W. Ochterski, P. Y. Ayala, K. Morokuma, G. A. Voth, P. Salvador, J. J. Dannenberg, V. G. Zakrzewski, S. Dapprich, A. D. Daniels, M. C. Strain, O. Farkas, D. K. Malick, A. D. Rabuck, K. Raghavachari, J. B. Foresman, J. V. Ortiz, Q. Cui, A. G. Baboul, S. Clifford, J. Cioslowski, B. B. Stefanov, G. Liu, A. Liashenko, P. Piskorz, I. Komaromi, R. L. Martin, D. J. Fox, T. Keith, M. A. Al-Laham, C. Y. Peng, A. Nanayakkara, M. Challacombe, P. M. W. Gill, B. Johnson, W. Chen, M. W. Wong, C. Gonzalez, J. A. Pople, Gaussian, Inc., Wallingford CT, 2004. 
[30] W. H. Miller, N. C. Handy, J. E. Adams, J. Chem. Phys. 1980, 72, 99.

[31] A. Fernandez-Ramos, J. A. Miller, S. J. Klippenstein, D. G. Truhlar, Chem. Rev. 2006, 106, 4518.

[32] W. Forst, Unimolecular Reactions, Cambridge University Press, Cambridge, U.K., 2003.

[33] J. R. Barker, Int. J. Chem. Kinet. 2001, 33, 232.

[34] J. Wang, R. M. Wolf, J. W. Caldwell, P. A. Kollman, D. A. Case, J. Comput. Chem. 2004, 25, 1157.

[35] J. R. Barker, N. F. Ortiz, Int. J. Chem. Kinet. 2001, 33, 246.

[36] J. R. Barker, N. F. Ortiz, J. M. Preses, L. L. Lohr, A. Maranzana, P. J. Stimac, MultiWell-2.08 Software, University of Michigan, Ann Arbor, MI, 2007, http://aoss.engin.umich.edu/multiwell/.

[37] B. K. Mishra, N. Sathyamurthy, J. Phys. Chem. A 2007, $111,2139$.
[38] S. E. Wheeler, K. N. Houk, J. Chem. Theory Comput. 2009, 5, 2301.

[39] L. A. Curtiss, K. Raghavachari, P. C. Redfern, J. A. Pople, J. Chem. Phys. 2000, 112, 7374.

[40] M. J. Prather, C. M. Spivakovsky, J. Geophys. Res. 1990, 95, 18723.

[41] R. G. Prinn, R. F. Weiss, B. R. Miller, J. Huang, F. N. Alyea, D. M. Cunnold, P. J. Fraser, H. E. Hartley, P. G. Simmonds, Science 1995, 269, 187.

[42] J. G. Calvert, R. Atkinson, K. H. Becker, R. M. Kamens, J. H. Seinfeld, T. J. Wallington, G. Yarwood, The Mechanisms of Atmospheric Oxidation of Aromatic Hydrocarbons, Oxford University Press, Oxford, U.K., 2002.

[43] R. Volkamer, B. Klotz, I. Barnes, T. Imamura, K. Wirtz, N. Washida, K. H. Becker, U. Platt, Phys. Chem. Chem. Phys. 2002, 4, 1598. 


\section{Supporting Information:}

Tropospheric degradation of perfluorinated aromatics: A case of hexafluorobenzene Goran Kovačević and Aleksandar Sabljić

pages: 4

tables: 2

Table S1. Optimized geometrical parameters of hydroxyl radical, hexafluorobenzene, prereaction complex, transition state and adduct (bond lengths in $\AA$, angles in degrees).

\begin{tabular}{lll}
\hline \hline Parameters & UMP2/6-311G(d,p) & Experiment \\
\hline Hydroxyl radical & & \\
\hline $\mathrm{r}(\mathrm{O}-\mathrm{H})$ & 0.967 & $0.9706^{\mathrm{a}}$ \\
\hline Hexafluorobenzene & & \\
\hline$r(\mathrm{C}-\mathrm{C})$ & 1.394 & $1.394^{\mathrm{b}} \pm 0.007$ \\
$r(\mathrm{C}-\mathrm{F})$ & 1.332 & $1.327^{\mathrm{b}} \pm 0.007$ \\
\hline \hline
\end{tabular}

${ }^{\mathrm{a}}$ G. Herzberg, Molecular spectra and molecular structure; I. Spectra of Diatomic Molecules, D. Van Nostrand Company, Toronto, 1950.

${ }^{\mathrm{b}}$ A. Almenningen, O. Bastiansen, R. Seip, and M. Hans, Acta Chem. Scand. 18 (1964) 2115-2124.
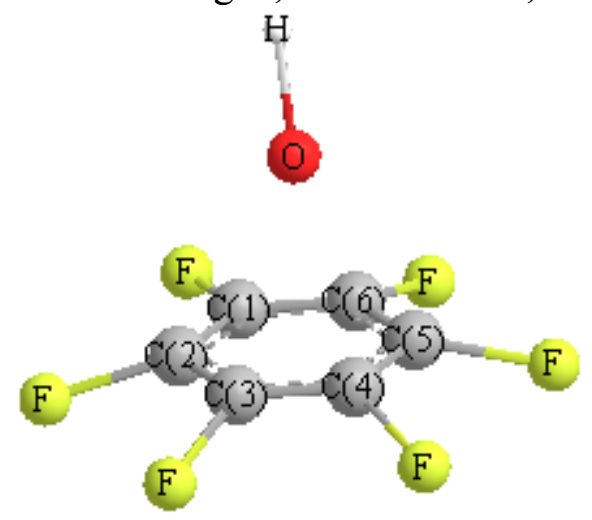

\begin{tabular}{ll}
\hline \hline Parameter & UMP2/6-311G(d,p) \\
\hline Prereaction complex & \\
\hline$r(\mathrm{C} 1-\mathrm{C} 2)$ & 1.393 \\
$r(\mathrm{C} 1-\mathrm{F})$ & 1.332 \\
$r(\mathrm{C} 1-\mathrm{O})$ & 3.089 \\
$r(\mathrm{O}-\mathrm{H})$ & 1.001 \\
$\theta(\mathrm{C}-\mathrm{C}-\mathrm{C})$ & 120.0 \\
$\theta(\mathrm{F}-\mathrm{C}-\mathrm{O})$ & 116.5 \\
$\theta(\mathrm{C}-\mathrm{O}-\mathrm{H})$ & 153.2 \\
$\theta(\mathrm{C}-\mathrm{C}-\mathrm{F})$ & 120.0 \\
$\phi(\mathrm{C}-\mathrm{C}-\mathrm{C}-\mathrm{C})$ & 0.0 \\
$\phi(\mathrm{C}-\mathrm{C}-\mathrm{C}-\mathrm{F})$ & 179.6 \\
$\phi(\mathrm{F}-\mathrm{C}-\mathrm{C}-\mathrm{F})$ & 0.0 \\
\hline \hline
\end{tabular}




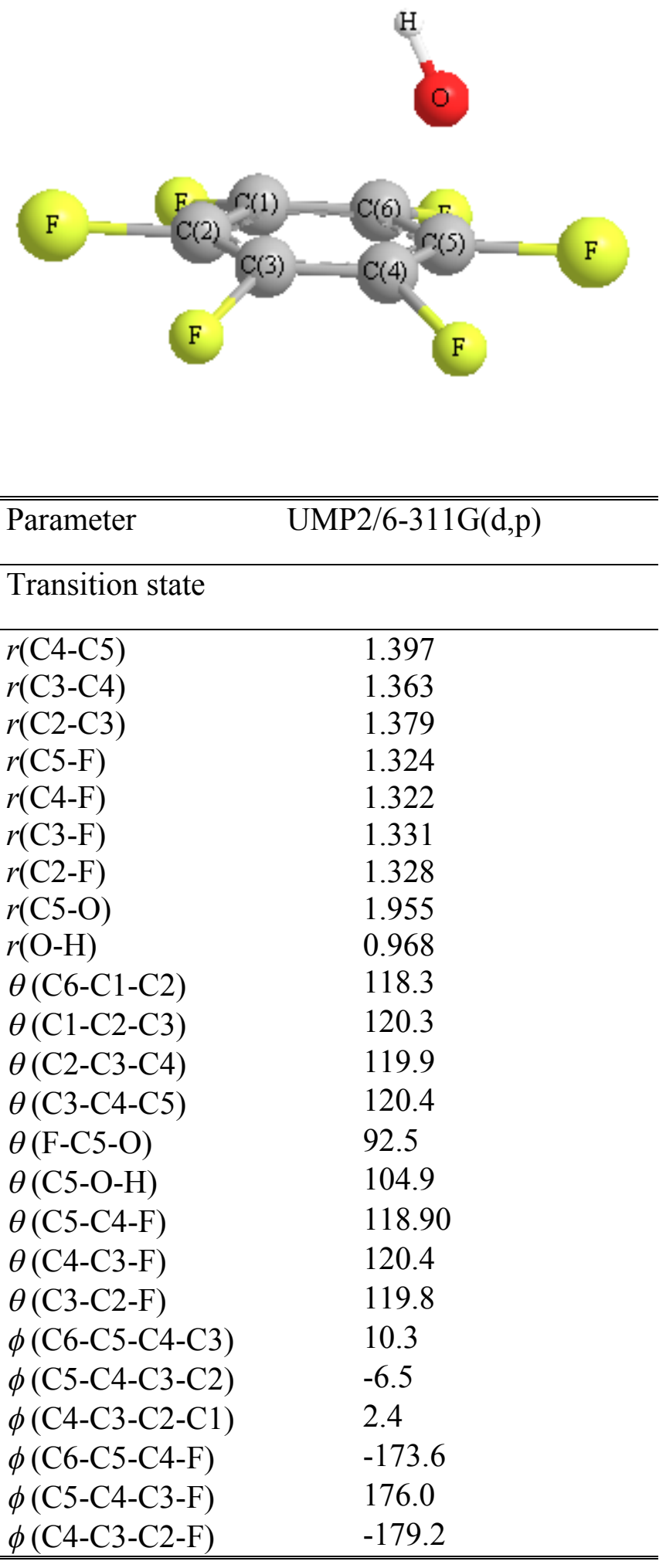




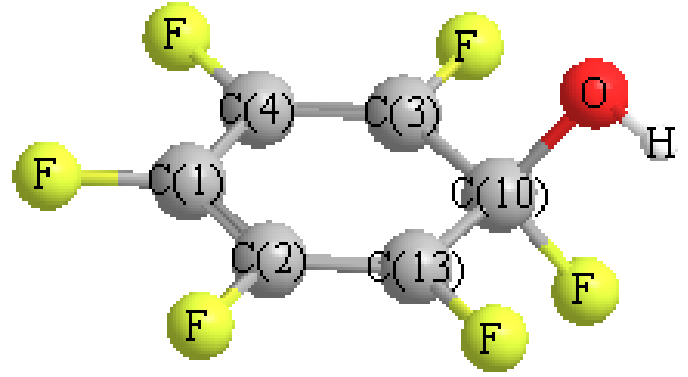

\begin{tabular}{ll}
\hline \hline Parameter & UMP2/6-311G(d,p) \\
\hline 1-Hydroxy-hexafluoro-2,4-cyclohexadienyl \\
radical (adduct) \\
\hline$r(\mathrm{C} 10-\mathrm{C} 3)$ & \\
$r(\mathrm{C} 3-\mathrm{C} 4)$ & 1.50 \\
$r(\mathrm{C} 1-\mathrm{C} 4)$ & 1.34 \\
$r(\mathrm{C} 10-\mathrm{F})$ & 1.42 \\
$r(\mathrm{C} 3-\mathrm{F})$ & 1.38 \\
$r(\mathrm{C} 4-\mathrm{F})$ & 1.33 \\
$r(\mathrm{C} 1-\mathrm{F})$ & 1.33 \\
$r(\mathrm{C} 10-\mathrm{O})$ & 1.32 \\
$r(\mathrm{O}-\mathrm{H})$ & 1.40 \\
$\theta(\mathrm{C} 13-\mathrm{C} 10-\mathrm{C} 3)$ & 0.96 \\
$\theta(\mathrm{C} 10-\mathrm{C} 3-\mathrm{C} 4)$ & 111.8 \\
$\theta(\mathrm{C} 3-\mathrm{C} 4-\mathrm{C} 1)$ & 123.5 \\
$\theta(\mathrm{C} 4-\mathrm{C} 1-\mathrm{C} 2)$ & 120.2 \\
$\theta(\mathrm{C} 1-\mathrm{C} 10-\mathrm{O})$ & 120.8 \\
$\theta(\mathrm{C} 10-\mathrm{O}-\mathrm{H})$ & 135.3 \\
$\theta(\mathrm{F}-\mathrm{C} 10-\mathrm{O})$ & 107.0 \\
$\phi(\mathrm{C} 13-\mathrm{C} 10-\mathrm{C} 3-\mathrm{C} 4)$ & 103.4 \\
$\phi(\mathrm{C} 10-\mathrm{C} 3-\mathrm{C} 4-\mathrm{C} 1)$ & -5.6 \\
$\phi(\mathrm{C} 3-\mathrm{C} 4-\mathrm{C} 1-\mathrm{C} 2)$ & 3.7 \\
$\phi(\mathrm{C} 13-\mathrm{C} 10-\mathrm{C} 3-\mathrm{F})$ & -1.1 \\
$\phi(\mathrm{C} 10-\mathrm{C} 3-\mathrm{C} 4-\mathrm{F})$ & 176.7 \\
$\phi(\mathrm{C} 3-\mathrm{C} 4-\mathrm{C} 1-\mathrm{F})$ & -178.3 \\
$\phi(\mathrm{F}-\mathrm{C} 10-\mathrm{O}-\mathrm{H})$ & -179.9 \\
\hline & 180.0 \\
\hline
\end{tabular}


Table S2. Equilibrium constants $K(T)$ for the association of $\mathrm{OH}$ radical and hexafluorobenzene into the prereaction complex, the unimolecular reaction rates $\left(k_{\text {diss }}\right)$ for dissociation of the prereaction complex and final relative populations $(f)$ of adduct after 1000 collisions modeled with the Gillespie stochastic model. The relative translation of $\mathrm{OH}$ radical with respect to hexafluorobenzene in the prereaction complex was treated as a two-dimensional particle-in-thebox.

\begin{tabular}{lcll}
\hline \hline $\mathrm{T} / \mathrm{K}$ & $K(T) / \mathrm{dm}^{3} \mathrm{~mol}^{-1}$ & \multicolumn{1}{c}{$k_{\text {diss }} / \mathrm{s}^{-1}$} & $f$ \\
\hline 230 & $3.9 \mathrm{E}-1$ & $9.53 \mathrm{E} 9$ & $1.93 \mathrm{E}-5$ \\
240 & $2.5 \mathrm{E}-1$ & $1.39 \mathrm{E} 10$ & $2.38 \mathrm{E}-5$ \\
250 & $1.7 \mathrm{E}-1$ & $1.87 \mathrm{E} 10$ & $3.15 \mathrm{E}-5$ \\
260 & $1.2 \mathrm{E}-1$ & $2.44 \mathrm{E} 10$ & $4.07 \mathrm{E}-5$ \\
270 & $8.4 \mathrm{E}-2$ & $3.27 \mathrm{E} 10$ & $4.97 \mathrm{E}-5$ \\
280 & $6.1 \mathrm{E}-2$ & $4.08 \mathrm{E} 10$ & $6.34 \mathrm{E}-5$ \\
290 & $4.6 \mathrm{E}-2$ & $5.22 \mathrm{E} 10$ & $7.56 \mathrm{E}-5$ \\
300 & $3.5 \mathrm{E}-2$ & $6.27 \mathrm{E} 10$ & $9.65 \mathrm{E}-5$ \\
310 & $2.7 \mathrm{E}-2$ & $7.75 \mathrm{E} 10$ & $1.15 \mathrm{E}-4$ \\
320 & $2.1 \mathrm{E}-2$ & $9.05 \mathrm{E} 10$ & $1.45 \mathrm{E}-4$ \\
330 & $1.7 \mathrm{E}-2$ & $1.09 \mathrm{E} 11$ & $1.68 \mathrm{E}-4$ \\
\hline \hline
\end{tabular}

plus corrected $\mathrm{G} 3$ energies by $1.07 \mathrm{kcal} \mathrm{mol}^{-1}$.

\begin{tabular}{lclc}
\hline \hline $\mathrm{T} / \mathrm{K}$ & $K(T) / \mathrm{dm}^{3} \mathrm{~mol}^{-1}$ & $k_{\text {diss }} / \mathrm{s}^{-1}$ & $f$ \\
\hline 230 & 58.9 & $9.53 \mathrm{E} 9$ & $1.93 \mathrm{E}-5$ \\
240 & 49.1 & $1.39 \mathrm{E} 10$ & $2.38 \mathrm{E}-5$ \\
250 & 33.7 & $1.87 \mathrm{E} 10$ & $3.15 \mathrm{E}-5$ \\
260 & 25.5 & $2.44 \mathrm{E} 10$ & $4.07 \mathrm{E}-5$ \\
270 & 17.0 & $3.27 \mathrm{E} 10$ & $4.97 \mathrm{E}-5$ \\
280 & 12.1 & $4.08 \mathrm{E} 10$ & $6.34 \mathrm{E}-5$ \\
290 & 9.16 & $5.22 \mathrm{E} 10$ & $7.56 \mathrm{E}-5$ \\
300 & 6.35 & $6.27 \mathrm{E} 10$ & $9.65 \mathrm{E}-5$ \\
310 & 4.80 & $7.75 \mathrm{E} 10$ & $1.15 \mathrm{E}-4$ \\
320 & 3.49 & $9.05 \mathrm{E} 10$ & $1.45 \mathrm{E}-4$ \\
330 & 2.66 & $1.09 \mathrm{E} 11$ & $1.68 \mathrm{E}-4$ \\
\hline \hline
\end{tabular}

